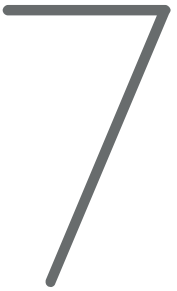

\title{
EL DISEÑADOR Y LA INDUSTRIA GRÁFICA
}

Sr. Francisco Valdivieso B. 
Según las conclusiones del primer diagnóstico de la Industria Gráfica Ecuatoriana elaborado por la Asociación de Industriales Gráficos del Ecuador en octubre de 1986, existen en el país 202 empresas con características industriales en nuestro sector; en su mayor parte pequeñas y medianas.

El Ecuador, sobre todo en la última década, ha tenido un desarrollo importante en la industria gráfica, desarrollo que ha permitido no solamente solidificar el prestigio de esta industria en nuestro país, sino presentar una imagen solvente en el contexto latinoamericano.

Libros, revistas, catálogos de arte y demás impresos han tenido tal desarrollo en el país que nos ha permitido, con legítimo orgullo, considerar que estamos en condiciones de comparación con similares productos de otros países latinoamericanos.

Si bien esta realidad sobre la calidad de nuestro impreso nace por mayor exigencia del mercado, nace también por la voluntad del gráfico ecuatoriano en su afán de mejorar el producto a pesar de tantas limitaciones existentes. La labor gremial de nuestra asociación se encamina a incrementar en el empresario gráfico la conciencia por un mejor rendimiento, por un cambio en la filosofía de trabajo en función de calidad, productividad, rendimiento.

En el contexto de esta nueva imagen de nuestra gráfica, ha tenido una importancia relevante la presencia del diseñador gráfico. No existe producto gráfico sin diseño previo; no existe expresión gráfica sin creación previa; el diseño gráfico nace con la invención de la imprenta. Una tarjeta de visita, un catálogo de arte o un simple formulario, no existirían sin la presencia de aquel cajista tipográfico, diseñador autodidacta. 


\section{El Diseño Gráfico en el concepto académico}

El Diseño Gráfico, como profesión, es nuevo en el Ecuador. Creo que no existe todavía el primer egresado en ningún instituto nacional. Salvo pequeñas excepciones, nuestros impresos han sido diseñados por personas con inquietudes afines al dibujo o por personas de cierta sensibilidad artística y buen gusto, que han podido plasmar, a través del impreso, sus ideas gráficas.

Una de las causas que ha limitado el crecimiento de nuestra industria es la falta de talleres especializados. La gama de impresos diferentes es inmensa. No existe complementación entre talleres: una empresa mediana imprime en offset y tipografía; hace fotomecánica, encuaderna, pretende imprimir tarjetas de visita, estuches de farmacéutica, formularios, afiches y libros de arte, y, además pretende utilidades a fin de año. Esto, lamentablemente, es una tendencia de la industria gráfica ecuatoriana.

Como se puede suponer, las necesidades de diseño gráfico de esta empresa son tan diferentes como la gama de productos a imprimir. Debe contactar a un diseñador polifacético (eso no existe) o contratar a varios por especialización.

Si bien es cierto que los periódicos, las gráficas que imprimen revistas, las gráficas que imprimen libros exclusivamente, pueden justificar la creación de departamentos de diseño, también lo es que son empresas atípicas en el sector.

La falta de especialización conlleva un riesgo para el gráfico. La diversidad de productos nos obliga a una "despersonalización" de los mismos, nos impide la eficiencia de la especialización.

En el caso de la empresa que represento, "Imprenta Mariscal", este fenómeno se nota claramente, por diferentes causas hacemos una infinidad de productos, lo cual ha impedido la creación del departamento de diseño mencionado anteriormente. Trabajamos con varios diseñadores "Freelance", lo cual nos ha permitido conocerlos, conocer su natural especialización, conocer sus ambiciones y problemas; conocer y tratar de comprender sus necesidades en nuestra diaria comunicación. 
Es posible que algunas de estas personas no hayan recibido educación académica en diseño gráfico; otros son egresados de universidades americanas; pero todos colaboran con nosotros en el afán de que el documento final, el producto impreso, tenga la mejor presentación posible.

El problema que tenemos en el diseño gráfico, más que por la parte subjetiva del mismo, la calidad de la ilustración o tipografía, nace por las limitaciones que tiene el diseñador en el acceso a lo que es la nueva tecnología de preimpresión.

El desarrollo de esta técnica ha sido impresionante; la tipografía se usa esporádicamente, las composer de ayer son obsoletas hoy, la foto composición -tecnología de punta en nuestros países pero ya superada en otros- es inaccesible a nuestros diseñadores ya sea por costos o por falta de información oportuna, ya que en nuestros países el acceso a conocimientos sobre nueva tecnología está limitado a quien tiene la inquietud, el dinero y el tiempo suficientes para asistir a ferias internacionales.

Existen en Quito varios talleres de foto composición, talleres que dan servicio, talleres que en función de arriendo de terminales permiten al diseñador gráfico trabajar en pantalla, corregir en pantalla y, a través de un pequeño diskette, enviar la información al computador central. Una vez procesada y filmada esta información será devuelta en papel fotográfico para su posterior diagramación. Esta fórmula de trabajo parece ser la que se impondrá en el futuro.

En el mes de agosto del año pasado, el gobierno ecuatoriano promulgó la Ley de Fomento del Libro, ley reglamentada dos meses más tarde. Esta ley le permite al Ecuador producir más libros, crear más libros. Como ustedes saben, anteriormente era mucho más barato imprimir libros en el exterior. Esto fue causa para que la industria gráfica no haya tenido un desarrollo coherente en el campo editorial. Hoy día, gracias a esta ley, no sólo podemos imprimir nuestros libros, sino que estamos en mejores condiciones que nuestros colegas latinoamericanos para imprimir libros para exportación. 
La Ley del Libro nos permite importar materia prima e insumos sin impuestos; facilita la creación de líneas de crédito en condiciones blandas; contempla la exoneración de impuesto a la renta para las empresas editoriales; concede tarifas preferenciales para el transporte del libro. En fin, el objetivo de la ley estimula la creación y producción del libro.

Todo esto permitirá que el campo de la preimpresión, diseño gráfico, diagramación y fotografía, se expanda. Y se expanda en mejores condiciones, ya que la edición de un nuevo libro creará un nuevo mercado. Se expanda por la posibilidad de la exportación del libro. Se expanda por la necesidad de mejorar un producto para poder competir.

Al exportar un libro no sólo exportamos el contenido, ya sea texto o fotografía: exportamos también el continente, la ilustración, el diseño, la impresión. Exportamos la calidad de comunicadores que somos los gráficos.

Por otro lado, como dije al inicio de mi intervención, el desarrollo en calidad y en cantidad del impreso ecuatoriano, nos permite, siguiendo con el ejemplo del libro, sustituir la importación del libro español, fuera de mercado por la revaluación de la peseta. Este inmenso mercado, que debe ser cubierto por la gráfica latinoamericana, constituye para nosotros un reto importantísimo; un reto que estamos dispuestos a afrontar, contando para ello con el trabajo de ustedes: contando con los elementos que componen la industria gráfica, esto es, preimpresión, impresión y acabado. Y dentro de la preimpresión, aquello que es más importante: la creación del producto.

Teniendo el diseñador gráfico la decisión sobre lo que va a ser impreso, debe tomar en cuenta, preferentemente, la forma de expresar, dentro de su trabajo, su propia identidad. Identidad como ecuatoriano, como latinoamericano. Respetar aquello que está en nuestra historia, que está en nuestra gráfica ancestral. Y cuando me refiero a gráfica, me refiero a las diferentes expresiones de nuestro ser, de nuestro arte, de nuestro arte popular, de nuestra propia personalidad. Creo que sería injusto, como gráficos ecuatorianos, tratar de implantar una identidad ajena. No sacamos nada tratando de importar, de copiar diseño de otros países, cuando en el nuestro tenemos una fuente inagotable de recursos 
para poder expresar nuestros sentimientos. Al fin y al cabo, el documento final es el impreso y él llevará el mensaje que hemos decidido enviar.

Quiero hacer hincapié en este concepto: un impreso no es únicamente el texto, la fotografía o el diseño; es el contexto, es la unión de voluntades con un mismo fin, confirmemos a través del impreso nuestra personalidad gráfica, nuestra cultura gráfica.

Dice Gian Calvi "casi todos los artistas latinoamericanos que forman el sector de la imagen utilizan como referencia una imagen que no es latinoamericana. La gran mayoría de estos artistas tienen como referencia, por tradición escolar, por formación, el uso del modelo de imagen que no es el de Latinoamérica".

Si es que yo, como gráfico ecuatoriano, como representante de un gremio, puedo dar algún consejo a ustedes que como profesionales manejarán el diseño gráfico en el Ecuador, será el de tratar de rescatar, tratar de promover nuestra propia identidad, tratar de producir imágenes claramente ecuatorianas.

Quiero aprovechar esta oportunidad para, a pesar de las limitaciones propias de la falta de conocimientos, hacer algunas reflexiones sobre lo que en preimpresión está ocurriendo actualmente en el mundo. Quiero hacer referencia a lo que pude advertir en la feria "Imprinta" realizada en febrero en la ciudad de Dusseldorf.

Hoy día una computadora personal, un pequeño equipo, puede, con la ayuda de programas desarrollados inclusive en español, ser un instrumento de trabajo muy importante para un diseñador de libros y revistas. Por ejemplo, puede realizar el trabajo de complejos equipos de fotocomposición. Con una impresora láser tendrá pruebas para el cliente en la tipografía final, y con una filmadora podrá armar libros y revistas en tiempos muy cortos y con inversiones relativamente bajas.

Estos programas están en el mercado; en la secretaría de nuestra asociación tenemos abundante información al respecto. 
La nueva tecnología, en cuanto al proceso de la palabra, se ha desarrollado en tal forma que aquello que hoy día es novedad mañana será rutinario.

En cuanto al proceso de la imagen, la tendencia es la eliminación de la separación de colores por el sistema tradicional. Fabricantes de película como Dupont, han decidido suspender la producción de películas de tono continuo. El scanner ha desarrollado nuevas técnicas a partir de la digitalización de la información existente en un original transparente $\mathrm{u}$ opaco. La conformación electrónica del punto por rayo láser ha revolucionado la calidad del impreso.

Con un scanner podemos hacer corrección de color sobre valores previamente conocidos por nosotros. Con el uso de máscaras electrónicas, podemos variar el color de parte del original sin afectar al resto, sobreponer imágenes, etc. Esto no es ciencia ficción; es tecnología común en países industrializados y es la tendencia en los nuestros. Existen en el país dos equipos de última generación.

Estas consideraciones las he comentado pues pienso que organismos como el Instituto Metropolitano de Diseño, la Universidad Tecnológica Equinoccial o esta Universidad, deben contemplar en sus planes de estudio la existencia real de una tecnología nueva que, si bien no podrá sustituir la creación humana, ha creado instrumentos técnicos para facilitar esta tarea.

La Asociación de Industriales Gráficos tiene acceso, a través de convenios internacionales de capacitación o de cursos y seminarios, al análisis de esta nueva tecnología, estos contactos los ponemos a disposición de ustedes.

En el mes de octubre del próximo año tendrá lugar en el Ecuador el décimo segundo Congreso Latinoamericano de la Industria Gráfica y, simultáneamente, se celebrarán encuentros técnicos de los diferentes sectores que conforman nuestra actividad; uno de ellos será relativo a preimpresión.

Estos encuentros constituirán foros en los que podremos analizar temas puntuales de cada actividad, como planes de estudio, mercado, 
acceso a nueva tecnología, comercio exterior del diseño gráfico, tendencias a nivel Latinoamericano, etc.; se prevé la asistencia de expositores de alto nivel y se tratará de crear exhibiciones del trabajo a nivel latinoamericano; se procurará conseguir que nuestros proveedores no se preocupen únicamente de la venta de sus productos sino que nos ayuden en capacitación.

Nuestra Asociación, como anfitriona del Congreso y de los encuentros técnicos, deberá coordinar la organización de los mismos. Quiero invitar a quienes quieran participar de esta comisión, ya que no se puede aceptar que tanta responsabilidad quede en manos de pocas personas.

Como recomendaciones del sector al que pertenezco, para este III Encuentro que se realiza sobre el Diseño en general y el Diseño Gráfico en particular, me atrevería a proponer los siguientes aspectos:

- Impulsar la realización de cursos y seminarios sobre Diseño Gráfico, utilizando para ello la estructura académica existente y las posibilidades ofrecidas por instituciones internacionales, demandando de nuestro gobierno la ayuda necesaria.

- Ratificar la importancia del Diseño Gráfico como profesión indispensable en nuestra institución.

- Organizar pasantías temporales en tal forma que el estudiante de diseño pueda, a través de la industria gráfica privada, poner en práctica sus conocimientos y comprender los problemas de la misma.

- Difundir bibliografía relativa al Diseño Gráfico, a través de boletines y revistas, sobre todo, difundir aquello que se edite con relación a congresos y seminarios a nivel latinoamericano, a los cuales la Asociación de Industriales Gráficos tiene acceso.

- Prestar el máximo apoyo a la realización del próximo Congreso Latinoamericano de industria gráfica que se realizará en el Ecuador, así como al encuentro específico sobre Diseño Gráfico. 
- Tratar de agrupar en una entidad gremial a los diseñadores gráficos, fotógrafos, ilustradores, y diagramadores, a fin de impulsar y defender el sector.

Como gráfico, quiero agradecer la oportunidad de haber participado en este encuentro. Yo no vine aquí a dar una charla; vine a aprender, vine a comprender y a conocernos quienes estamos en el mismo campo y tenemos una meta común: la de tratar, a partir de una hoja de papel, de expresar nuestras inquietudes. 